\title{
On the Social Desirability of Patents for Sequential Innovations in a Vertically Differentiated Market*
}

\author{
Luca Lambertini" ${ }^{\#}$ Piero Tedeschi ${ }^{\S}$ \\ \# Department of Economics, University of Bologna \\ Strada Maggiore 45, 40125 Bologna, Italy \\ fax: +39-051-2092664, e-mail: lamberti@spbo.unibo.it \\ $\S$ Department of Economics, University of Padua \\ Via del Santo 33, 35123 Padova, Italy \\ fax: +39-049-8274221, e-mail: tedeschi@decon.unipd.it
}

April 11, 2000

\begin{abstract}
We consider a market for vertically differentiated goods where firms enter over time, after having developed innovations characterised by different quality levels. We show that the adoption of a patent system limiting the quality range avalable to later entrants is socially undesirable, in that it builds a barrier to entry to the advantage of the first innovator.
\end{abstract}

J.E.L. Classification: L12, L13, O31

Keywords: innovation, patent height, product quality

*We thank Vincenzo Denicolò for useful comments. The usual disclaimer applies. 


\section{Introduction}

An apparently well established result in the theory of vertically differentiated oligopoly states that earlier entrants supply goods of higher quality than later entrants, in that the high-quality products earn higher profits than low-quality alternatives (see, inter alia, Gabszewicz and Thisse, 1979, 1980; Shaked and Sutton, 1982, 1983; Donnenfeld and Weber, 1995). A general proof of this result for every convex fixed-cost function of quality improvement is provided by Lehmann-Grube (1997). ${ }^{1}$

In this literature, quality is thought of as being the result of firms' R\&D activity, although this aspect is not explicitly tackled. This is done instead in a few recent papers where firms' efforts in developing quality is described in details (Dutta et al., 1995; Rosenkranz, 1995; 1997; van Dijk, 1996). In particular, van Dijk (1996) investigates the design of patent height in a duopoly model where quality and time are measured along the same dimension. ${ }^{2}$ This accounts for the idea that quality improvements take time. Adopting a model where the market is only partially served under monopoly and fully served under duopoly, van Dijk considers a patent system establishing that later innovators can enter the market if and only if they supply sufficient quality improvements as compared to incumbents (i.e., earlier innovators). van Dijk proves that the patent system does not affect the evolution of market structure as compared to the situation without patents. Moreover, he shows that later entrants may gain by producing goods whose quality is higher than the first innovator's. This result is due to the fact that it is more profitable to be the improver rather than the original innovator, in line with well known findings by previous research in the field of vertical differentiation.

We investigate a model of vertical differentiation where (i) partial market coverage emerges at equilibrium independently of the number of firms; (ii) time and quality are separate dimensions; and (iii) costs are convex in quality. Hypotheses (ii) and (iii) amount to assuming that the development of superior quality levels is not necessarily correlated with the time span over

\footnotetext{
${ }^{1}$ Aoki and Prusa (1997) adopt a specific case of the cost function analysed by LehmannGrube, to investigate the consequences on profits, consumer surplus and social welfare of the timing of investment in product quality in a vertically differentiated duopoly where the market stage is played in the price space. See also Lambertini (1999).

${ }^{2}$ The optimal design of patents in terms of their breadth and length, and imitations alongside the patent, are analysed in several contributions (Gilbert and Shapiro, 1990; Klemperer, 1990; Scotchmer and Green, 1990; Gallini, 1992; Denicolò, 1996).
} 
which R\&D activity is carried out, and we allow for the choice of quality to be dictated by strategic incentives alone. That is, we take the view that a later entrant may supply lower quality product than the incumbent's, if it is profitable to do so. The time horizon is infinite, and two firms may enter the market at different dates, which are exogenously fixed. Under specific assumptions, we prove that it is convenient for the later entrant to produce a lower quality than the first innovator's, for the following reason. If the later innovator enters with a quality lower than the first innovator, both firms' profits are positive. Otherwise, when the second innovator enters with a higher quality, her profits are nil due to the fact that the incumbent finds it optimal to produce a limit quality, larger than the optimal monopoly quality, such that entry is blockaded and the first innovator remains a monopolist. In contrast with van Dijk's findings, this result allows us to conclude that a patent system requiring any given improvement on the incumbent's quality is socially undesirable, in that it produces an everlasting monopoly. The same holds for a patent system covering a subset of the product range below the incumbent's quality, if the extent of the patent's height is larger than a critical threshold.

Several real-world examples can be found to match with our theoretical setting. For instance, consider the evolution of the market for CD players (CDPs). Early innovators, Philips and Sony, first introduced top-notch CDPs in 1982. The diffusion of low-priced CDPs started in the late ' $80 \mathrm{~s}$, with the same brands as well as several others. The same holds for the adoption of kevlar in the manufacturing of loudspeaker cones, originally introduced by Bowers \& Wilkins in expensive loudspeaker systems, and subsequently adopted by B\&W and many other manufacturers in more popular products.

One could recast our model in terms of a more general perspective concerning the optimal behaviour of firms simultaneously activating R\&D investments for innovations based on the same technology but eventually leading to marketable products characterised by some degree of substitutability, as in Cardon and Sasaki (1998). This is related, but not equivalent to, the problem of sequential patent races starting at different points in time, where later innovations must not infringe upon existing patents on earlier innovations (see Scotchmer, 1991, 1996; Green and Scotchmer, 1995; O’Donoghue, 1998; O'Donoghue, Scotchmer and Thisse, 1998).

The remainder of the paper is structured as follows. The basic model of vertical differentiation is laid out in section 2. Section 3 describes the two alternative entry games, where (i) the first entrant produces a high-quality 
good while the second entrant produces a low-quality good; and (ii) the opposite situation where the second entrant sells a good of higher quality than the incumbent's. Section 4 contains the evaluation of the effects of patents on market structure, assessing their social desirability. Finally, section 5 provides concluding remarks.

\section{The model}

Consider the following full-information setting. Let a market for vertically differentiated products exist over $t \in[0, \infty)$. Two single-product firms, labelled as 1 and 2, produce goods of different qualities, $q_{1}$ and $q_{2} \in[0, \infty)$, through the same technology, $C_{i}\left(q_{k}\right)=c q_{k}^{2}$, with $k=H, L$ and $i=1,2$. Development costs $C_{i}\left(q_{k}\right)$ are evaluated at the time $t_{i}$ when firm $i$ enters the market. ${ }^{3}$ As usual, these costs can be interpreted as fixed costs due to the R\&D effort needed to produce a certain quality, while variable production costs are negligible. Hence, without further loss of generality, we assume them to be nil. We characterize the technology represented by the above cost function as follows:

Assumption 1 Suppose firm $i$ develops a good of quality $\widehat{q}$, at cost $C_{i}(\hat{q})=$ $c \widehat{q}^{2}$. Then she can supply the market with any quality $q \in(0, \hat{q})$ without any additional costs. Once into the market, the firm cannot invest any more resources in $R \& D$.

The above amounts to assuming that any change in the quality level implies adjustment costs if and only if the change takes the form of a quality increase. ${ }^{4}$ Conversely, once firm $i$ has borne the cost of developing a given quality, she may decide to decrease the quality of her product costlessly. For later reference, we define $[0, \hat{q}]$ as the quality production set of the firm.

As to the design of the patent system, we can outline three alternative situations, analogous to some of those discussed in van Dijk (1996, pp. 159$61)$ :

\footnotetext{
${ }^{3}$ van Dijk (1996, p. 154) assumes that quality and time coincide, with $C_{i}(q)=t_{i}=q_{i}$.

${ }^{4}$ One could assume that adjustment costs be sufficiently large to make it unprofitable for firms to modify quality after the initial development phase. However, under full information, any such behaviour would clearly be irrational. Therefore, adjustment costs can be expected not to be borne by either firm at equilibrium.
} 
Patent System 1 The patent's length is infinite. If the first innovator develops quality $\hat{q}$, then the height of the patent system covers the interval $[0, \hat{q}]$, so that the second innovator must produce $\tilde{q}>\hat{q}$ in order not to infringe the patent over the first innovation.

Patent System 2 The patent's length is infinite. If the first innovator develops quality $\hat{q}$, then the patent covers the interval $[0, \hat{q}+\varepsilon]$, with $\varepsilon>0$. Then, the second innovator must produce $\tilde{q}>\hat{q}+\varepsilon$ in order not to infringe the patent over the first innovation.

Patent System 3 The patent's length is infinite. If the first innovator develops quality $\hat{q}$, then the patent covers the interval $[\hat{q}-\varepsilon, \widehat{q}]$, with $\varepsilon>0$. Then, the second innovator must produce $\tilde{q}<\hat{q}-\varepsilon$ or $\widetilde{q}>\hat{q}$ in order not to infringe the patent over the first innovation.

Observe that patent system 2 imposes a minimum quality improvement $\varepsilon$, arbitrarily large, on the part of the second entrant. That is, the protection ensured by the patent to the incumbent is strictly larger than the incumbent's quality production set, $[0, \hat{q}]$. Patent system 3 covers a proper subset of the incumbent's quality production set. A fourth patent system would be one that covers only $\hat{q}$. This is immediately ruled out as it is obvious that the incentive toward product differentiation suffices to guarantee that later entrants would never produce $\hat{q}$.

Products are offered on a market where consumers have unit demands, and buy if and only if the net surplus derived from consumption $v_{\theta}\left(q_{k}, p_{i}\left(q_{k}\right)\right)=$ $\theta q_{k}-p_{i}\left(q_{k}\right) \geq 0$, where $p_{i}\left(q_{k}\right)$ is the unit price charged by firm $i$ on a good of quality $q_{k}$, purchased by a generic consumer whose marginal willingness to pay is $\theta \in[0, \bar{\theta}]$. We assume that $\theta$ is uniformly distributed with density one over such interval, so that the total mass of consumer is $\bar{\theta}$. Assuming that the lower bound to $\theta$ is zero implies that, throughout the following analysis, we will consider partial market coverage only.

Firms' entry dates are exogenous. Firm 1 enters at date $t_{1} \geq 0$; in the remainder, we shall label the first entrant as the leader. Firm 2 enters at date $t_{2} \in\left[t_{1}, \infty\right)$, and we shall refer to her as the follower. However, we do not assume that quality level and entry time are positively related. A firm might enter the market early with a high quality or late with a low quality, depending upon strategic incentives. Over the time span $\left[t_{1}, t_{2}\right)$, the leader remains a monopolist. At any $t \in\left[t_{1}, t_{2}\right)$, firm 1 maximizes w.r.t. price the 
instantaneous revenues:

$$
R_{M}=p_{M} x_{M}=p_{M}\left(\bar{\theta}-\frac{p_{M}}{q_{M}}\right)
$$

where $p_{M}$ is monopoly price and $x_{M}=\bar{\theta}-p_{M} / q_{M}$ is market demand. We can prove the following:

Lemma 1 The leader's revenues during the monopoly phase are everywhere increasing in quality.

Proof. The first order condition (FOC) of the monopolist w.r.t. $p_{M}$ is:

$$
\frac{\partial R_{M}}{\partial p_{M}}=\frac{\bar{\theta} q_{M}-2 p_{M}}{q_{M}}=0
$$

yielding $p_{M}=\bar{\theta} q_{M} / 2$ as the optimal monopoly price, so that (1) simplifies to:

$$
R_{M}=\frac{\bar{\theta}^{2} q_{M}}{4}
$$

which is everywhere increasing in $q_{M}$.

Concerning firms' behavior after the follower's entry, we are going to examine two alternative perspectives:

A. The follower enters at $t_{2}$ with a product whose quality is lower than the leader's. We label this case as high-quality leadership.

B. The follower enters at $t_{2}$ with a product whose quality is higher than the leader's. We label this case as low-quality leadership.

In both cases, over $t \in\left[t_{2}, \infty\right)$, firms compete in prices. The solution concept is the subgame perfect equilibrium by backward induction. ${ }^{5}$ We borrow from Aoki and Prusa (1997) and Lehmann-Grube (1997) the assumption that downstream Bertrand competition is simultaneous. Market demands for the high- and low-quality good are, respectively:

$$
x_{H}=\bar{\theta}-\frac{p_{H}-p_{L}}{q_{H}-q_{L}}
$$

\footnotetext{
${ }^{5}$ In particular, we solve both stages in the duopoly regime through a simultaneous Nash equilibrium. This simplifies calculations withouth significantly affecting the main results.
} 
and

$$
x_{L}=\frac{p_{H}-p_{L}}{q_{H}-q_{L}}-\frac{p_{L}}{q_{L}}
$$

Duopoly revenue functions are $R_{H}=p_{H} x_{H}$ and $R_{L}=p_{L} x_{L}$. Solving for the price equilibrium, the revenue function of firm 1 can be rewritten in terms of qualities only, as follows: ${ }^{6}$

$$
\begin{aligned}
& R_{H}=\frac{4 \bar{\theta}^{2} q_{H}^{2}\left(q_{H}-q_{L}\right)}{\left(4 q_{H}-q_{L}\right)^{2}} \text { if } q_{1}=q_{H} \\
& R_{L}=\frac{\bar{\theta}^{2} q_{H} q_{L}\left(q_{H}-q_{L}\right)}{\left(4 q_{H}-q_{L}\right)^{2}} \text { if } q_{1}=q_{L}
\end{aligned}
$$

Per-period revenues accruing to the follower are defined residually. On the basis of expressions (6-7), previous literature, dealing with single-period models, established that the first entrant would choose to supply the high-quality good.

\section{$3 \quad$ The entry games}

Here, we briefly expose the outcomes of the two entry games, in order to outline firms' profit incentives which are going to shape the subgame perfect equilibrium of the model.

\subsection{High-quality leadership}

We first consider case $A$, where under monopoly $\left(t \in\left[t_{1}, t_{2}\right)\right)$

the first entrant (firm 1 ) supplies quality $q_{M}$, while in the duopoly regime $\left(t \in\left[t_{2}, \infty\right)\right)$ the first entrant produces $q_{H} \geq q_{M}$ and the second entrant (firm 2) produces $q_{L} \leq q_{H}$. Hence, the development cost born by firm 1 is that associated with $q_{H}$, i.e., $C_{1}\left(q_{H}\right)$, whose present value is $c q_{H}^{2} \cdot e^{-r t_{1}}$. The discounted flow of profits accruing to firm 1 is:

$$
\Pi_{1 H}=\int_{t_{1}}^{t_{2}} R_{M} \cdot e^{-r t} d t+\int_{t_{2}}^{\infty} R_{H} \cdot e^{-r t} d t-c q_{H}^{2} \cdot e^{-r t_{1}}
$$

\footnotetext{
${ }^{6}$ The proof is omitted here, as it is provided by several authors (Gabszewicz and Thisse, 1979; Choi and Shin, 1992; Motta, 1993; Aoki and Prusa, 1997; Lehmann-Grube, 1997).
} 
while the discounted profits to firm 2 are:

$$
\Pi_{2 L}=\int_{t_{2}}^{\infty} R_{L} \cdot e^{-r t} d t-c q_{L}^{2} \cdot e^{-r t_{2}}
$$

Instantaneous revenues $R_{M}, R_{H}$ and $R_{L}$ are given by $(3),(6)$ and (7), respectively. Firms non-cooperatively maximize discounted intertemporal profits w.r.t. qualities. The outcome of this game is summarized by the following:

Proposition 1 When the leader produces a higher quality than the rival, both firms enjoy positive profits, with $\Pi_{1 H}>\Pi_{2 L}>0$. Hence, over $t \in\left[t_{2}, \infty\right)$ the market is a duopoly.

Proof. See appendix A.1.

\subsection{Low-quality leadership}

Consider now the alternative case where, under duopoly, the leader (firm 1) produces $q_{L} \leq q_{M}$, while the follower (firm 2) produces $q_{H} \geq q_{M} \geq q_{L}$. The discounted flow of profits accruing to firm 1 is: ${ }^{7}$

$$
\Pi_{1 L}=\int_{t_{1}}^{t_{2}} R_{M} \cdot e^{-r t} d t+\int_{t_{2}}^{\infty} R_{L} \cdot e^{-r t} d t-c q_{M}^{2} \cdot e^{-r t_{1}}
$$

while the discounted profits to firm 2 are:

$$
\Pi_{2 H}=\int_{t_{2}}^{\infty} R_{H} \cdot e^{-r t} d t-c q_{H}^{2} \cdot e^{-r t_{2}}
$$

The outcome of this game is summarized by:

Proposition 2 When the leader produces a lower quality than the rival, $\Pi_{1 L}>0$ and $\Pi_{2 H}=0$. As a result, the incumbent remains a monopolist forever.

Proof. See appendix A.2.

\footnotetext{
${ }^{7}$ It might happen that $q_{M}<q_{L}$ (see appendix A2). In general, the cost function of the leader would write $C_{1}\left(\max \left\{q_{L}, q_{M}\right\}\right)$. This would not influence the main result we derive in this section. Moreover, as the ad interim monopoly revenues are everywhere increasing in $q_{M}$, it appears reasonable to consider the situation where the lead time be exploited as much as possible by the first entrant. This coincides with the view taken by van Dijk (1996, p. 156).
} 


\section{Evaluation of patent systems}

An intermediate step towards the design of the patent system consists in assessing firms' preferences as to their respective locations along the quality spectrum, based upon their pure profit incentives, i.e., independently of exogenous conditions imposed by a patent system.

Consider the perspective facing the first firm to innovate. The leader's decision as to whether to supply a low or a high-quality good depends on the comparative evaluation of the following profit flows:

$$
\begin{aligned}
& \Pi_{1 H}(x, \nu, \zeta)=\left(8 x^{3}(4 x-7)+(\nu-1)(4 x-1)^{3}\right) \frac{4 x^{2}-3 x+2}{2(4 x-1)^{6} \zeta} \\
& \Pi_{1 L}(\nu, \zeta)=\left[\frac{1}{64}(1-\nu)^{2}+\frac{7}{2304}\right] \bar{\theta}^{4} \zeta
\end{aligned}
$$

If $\Pi_{1 H}(x, \nu, \zeta)>\Pi_{1 L}(\nu, \zeta)$, then it is profitable to supply the high-quality good, and conversely if $\Pi_{1 H}(x, \nu, \zeta)<\Pi_{1 L}(\nu, \zeta)$. Hence, we have to evaluate the following expression:

$$
\begin{gathered}
\Pi_{1 L}(\nu, \zeta)-\Pi_{1 H}(x, \nu, \zeta)=\left\{\left[\frac{(1-\nu)^{2}}{64}+\frac{7}{2304}\right] \bar{\theta}^{4}+\right. \\
\left.-\left(8 x^{3}(4 x-7)+(\nu-1)(4 x-1)^{3}\right) \frac{\left(4 x^{2}-3 x+2\right)}{2(4 x-1)^{6}}\right\} \zeta
\end{gathered}
$$

It is immediate that (14) is positive if $\bar{\theta}$ is sufficiently large, i.e., if the market is sufficiently rich. However, we are also interested in evaluating (14) in terms of the time span separating entries by the two firms, that is, the length of the period $t_{2}-t_{1}$ wherein firm 1 remains a monopolist. To this aim, it is convenient to use the expression in (22) and the definition $\nu=\mu / \eta$, so as to rewrite both $\Pi_{1 L}(\nu, \zeta)$ and $\Pi_{1 H}(x, \nu, \zeta)$ in terms of $\mu$ and $\eta$ only, and to set $\bar{\theta}=1$. Under all practical respects, this re-parameterization permits to evaluate the profit perspectives of firm 1 in terms of $t_{1}$ and $t_{2}$, in that $\mu=e^{-r t_{1}}$ and $\eta=e^{-r t_{2}}$. The problem reduces to evaluating $\Pi_{1 L}(\mu, \eta)-$ $\Pi_{1 H}(\mu, \eta)$ in the admissible parameter range $\mu>\eta$. The implicit plot of $\Pi_{1 L}(\mu, \eta)-\Pi_{1 H}(\mu, \eta)=0$ in the space $\{\mu, \eta\}$ is in figure 1. 
Figure $1: \Pi_{1 L}(\mu, \eta)-\Pi_{1 H}(\mu, \eta)$

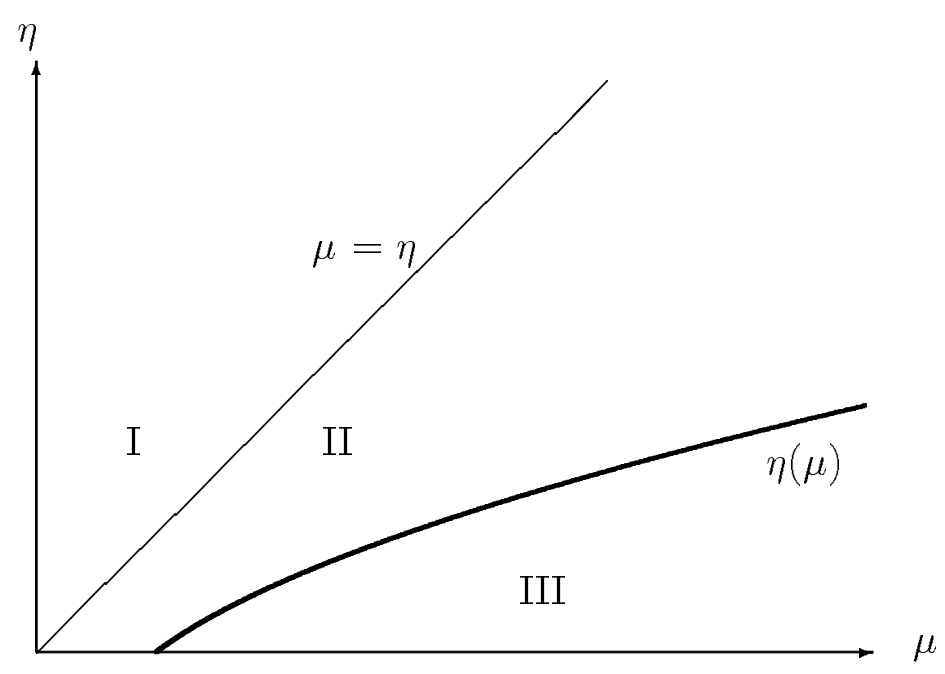

The thick curve denotes a solution $\eta(\mu)$ to $\Pi_{1 L}(\mu, \eta)-\Pi_{1 H}(\mu, \eta)=0$. Together with $\eta=\mu, \eta(\mu)$ allows us to partition the parameter space into three regions.

- Region I is not admissible, in that it must be $\mu=e^{-r t_{1}}>\eta=e^{-r t_{2}}$.

- In region II, $\Pi_{1 L}(\mu, \eta)<\Pi_{1 H}(\mu, \eta)$ in that $t_{2}$ is relatively close to $t_{1}$. The time span over which the leader remains a monopolist is too short to justify entering with a low quality good.

- In region III, $\Pi_{1 L}(\mu, \eta)>\Pi_{1 H}(\mu, \eta)$. The entry date of the follower is far enough in the future to make it more profitable entering with a low-quality good.

The above taxonomy highlights that there exists a trade-off between enjoying monopoly power as long as possible and enjoying an advantage over the rival when the latter enters the market and duopoly competition starts. We can summarize the foregoing discussion in the following: 
Proposition 3 The leader prefers to enter with a low-quality good if the transitory monopoly power outweighs the disadvantage of being the low-quality firm in the duopoly regime. Otherwise, the leader prefers to enter with a highquality good.

Observe that, if $\mu \in(0, \eta(\mu))$, the first entrant produces a (limit) low quality given by (41), that keeps the follower out of the market. That is, obliging the follower to employ a larger amount of resources in the development of a higher quality turns into a sort of predatory behavior preserving the monopoly power of firm 1.

In order to simplify the analysis, let us assume that a monopolist who started production at $t_{1}$ and ended it at $t_{2}$ would always produce an intermediate quality with respect to the low and the high quality leader. It is easy to check that a monopolist would produce the quality level $q_{M}=$ $\frac{1}{8} \frac{\bar{\theta}^{2}}{r c}\left(e^{-r t_{1}}-e^{-r t_{2}}\right)=\frac{1}{8 \gamma}(\nu-1)$. Our assumption amounts to saying that $q_{1 L} \leq \frac{1}{8 \gamma}(\nu-1) \leq q_{1 H}$.

Assumption $2 q_{1 L} \leq \frac{1}{8 \gamma}(\nu-1) \leq q_{1 H}$.

The assumption seems perfectly legitimate and ensures that, if there is a subgame perfect equilibrium with a low quality leadership, then that equilibrium implies that (i) the leader in the monopoly phase produces with quality $q_{M}=\frac{1}{8 \gamma}(\nu-1)$; and (ii) if the follower entered with a higher quality, it would respond with the quality $q_{1 L}=\frac{7}{48 \gamma \mu}$. However, we can prove that this is not an equilibrium because the follower finds it profitable to enter with a low quality when the leader tries to preempt the market, correctly anticipating that offering a superior quality would not pay off. Therefore, the only possible equilibrium is that with high quality leadership. This is proved in the following Proposition.

Proposition 4 In the absence of patent protection, a unique duopoly equilibrium exists over $t \in\left[t_{2}, \infty\right)$, with the leader supplying the high-quality good and the follower supplying the low-quality good.

Proof. See appendix A.3.

Since entry dates are exogenous, firms cannot influence the outcome of the game through the speed and/or intensity of their respective $R \& D$ activities. 
Indeed, the above Proposition reveals that the intertemporal model closely replicates the conclusions reached by previous literature dealing with static one-shot models, ${ }^{8}$ which points out the incentive for earlier entrants to supply high-quality goods. However, the static approach usually adopted so far cannot highlight the incentive for later innovators to enter the market in the lower part of the quality spectrum. Judging on the basis of the existing literature, one is lead to believe that later entrants produce low-quality goods because they have missed the chance of doing any better. On the contrary, our model depicts a situation where profit incentives drive newcomers towards inferior varieties. Moreover, the static approach is by definition unable to account for the possibility of trading off the market power attached to a dominant position in the duopoly regime against transitory monopoly power, which represents the prize for the earlier entrant. ${ }^{9}$

We are now able to evaluate the desirability of a patent regime. Consider patent system 1 . If it is adopted, the follower cannot enter the market profitably without infringing the leader's patent, and the leader can stay a monopolist forever by developing and patenting the limit quality (41), which can be kept asleep indefinitely. It is then trivial to prove that it is socially preferable to allow for a duopoly equilibrium with the follower producing the low-quality product. The same considerations hold, a fortiori, for patent system 2 . In the case of patent system 3 , if the height of the patent is small enough (that is, $\varepsilon \in\left[0, \max \left\{q_{M}, q_{1 H}\right\}-q_{2 L}\right]$ ), then the patent is actually inoperative and the follower may enter the market from below. Otherwise, if $\varepsilon>\max \left\{q_{M}, q_{1 H}\right\}-q_{2 L}$, entry is blockaded. This yields the following:

Proposition 5 Under convex costs of quality improvement and partial market coverage, a patent system limiting the height of later innovations in any direction is socially undesirable.

\footnotetext{
${ }^{8}$ Relevant references include Gabszewicz and Thisse (1979, 1980), Shaked and Sutton (1982, 1983), Motta (1993), Aoki and Prusa (1997) and Lehmann-Grube (1997).

${ }^{9}$ Modelling an R\&D race under uncertainty, Dutta et al. (1995) confirm the established wisdom, in that they find that the ad interim monopoly rent cannot counterbalance the advantage associated with high quality. However, their result relies upon a specific reduced form where production costs are completely absent.
} 


\section{Concluding remarks}

We have investigated a model of sequential entry in a market for vertically differentiated goods. The foregoing discussion points out that, when quality and time are separate dimensions, firms' strategic incentives are such that the follower will enter the market from below and gain positive profits. This is also socially preferable to the alternative situation where the first innovator produces a limit quality and remains a monopolist. As a consequence, it appears socially undesirable to adopt a patent system so as to protect the first innovator. 


\section{Appendix}

\section{A.1 Proof of Proposition 1}

Fxpressions (8) and (9) rewrite as follows:

$$
\begin{gathered}
\frac{\Pi_{1 H}}{\bar{\theta}^{2} e^{-r t_{2}}}=4 \frac{q_{H}^{2}\left(q_{H}-q_{L}\right)}{\left(4 q_{H}-q_{L}\right)^{2}}+\frac{\left(e^{-r t_{1}}-e^{-r t_{2}}\right) q_{M}}{4 e^{-r t_{2}}}-\frac{r c q_{H}^{2}}{e^{-r t_{2}} \bar{\theta}^{2}}= \\
=4 \frac{q_{H}^{2}\left(q_{H}-q_{L}\right)}{\left(4 q_{H}-q_{L}\right)^{2}}+\frac{\left(e^{-t_{1} r}-e^{-t_{2} r}\right) q_{M}}{4 e^{-t_{2} r}}-\gamma q_{H}^{2} \\
\frac{\Pi_{2 L}}{\overline{\bar{\theta}}^{2} e^{-r t_{2}}}=\frac{q_{H} q_{L}\left(q_{H}-q_{L}\right)}{\left(4 q_{H}-q_{L}\right)^{2}}-\frac{e^{-r t_{1}} r c}{\bar{\theta}^{2} e^{-r t_{2}}} q_{L}^{2}=\frac{q_{H} q_{L}\left(q_{H}-q_{L}\right)}{\left(4 q_{H}-q_{L}\right)^{2}}-\mu \gamma q_{L}^{2}
\end{gathered}
$$

where $\frac{r c}{e^{-r t_{2}} \bar{\theta}^{2}}=\gamma$ and $\mu=e^{-r t_{1}}$. First order conditions (FOCs) w.r.t. qualities are: ${ }^{10}$

$$
\begin{gathered}
\frac{\partial \Pi_{1 H}}{\partial q_{H}}=2 \bar{\theta}^{2} q_{H}\left[\frac{8 q_{H}^{2}-6 q_{H} q_{L}+4 q_{L}^{2}-\gamma\left(4 q_{H}-q_{L}\right)^{3}}{e^{t_{2} r}\left(4 q_{H}-q_{L}\right)^{3}}\right]=0 \\
\frac{\partial \Pi_{2 L}}{\partial q_{L}}=\frac{\bar{\theta}^{2}\left[4 q_{H}^{3}-7 q_{H}^{2} q_{L}-2 \mu \gamma q_{L}\left(4 q_{H}-q_{L}\right)^{3}\right]}{e^{t_{2} r}\left(4 q_{H}-q_{L}\right)^{3}}=0
\end{gathered}
$$

In order to simplify calculations, set $q_{L}=q$ and $q_{H}=x q$. This makes it possible to rewrite FOCs $(17)$ and $(18)$ in terms of $q / \gamma$, to obtain:

$$
-\frac{q^{2}}{\gamma^{2}}\left(-8 x^{2}+6 x-4+64 q x^{3}-48 q x^{2}+12 x q-q\right)=0
$$

From (17) and

$$
-\frac{q^{3}}{\gamma^{3}}\left(-4 x^{3}+7 x^{2}+128 \mu q x^{3}-96 \mu q x^{2}+24 \mu q x-2 \mu q\right)=0
$$

From (18). Excluding the trivial case $q=0$, the system (19-20) has the following solution:

$$
q(x)=\frac{2\left(4 x^{2}-3 x+2\right)}{(4 x-1)^{3}}
$$

\footnotetext{
${ }^{10}$ Second order conditions are met here as well as in the next section. They are omitted for the sake of brevity.
} 


$$
x=\frac{\alpha^{2}+\alpha(16 \mu+7)+256 \mu^{2}+80 \mu+49}{12 \alpha}
$$

where

$$
\begin{gathered}
\alpha=\left[8\left(512 \mu^{2}+240 \mu+321\right) \mu+343+\right. \\
\left.+24 \sqrt{3\left(5888 \mu^{3}+3552 \mu^{2}+2967 \mu+686\right) \mu}\right]^{1 / 3}
\end{gathered}
$$

The second first order condition could also be solved for $\mu$, obtaining:

$$
\mu=\frac{1}{2} x^{2} \frac{4 x-7}{q(4 x-1)^{3}}
$$

and using (21)it would yield:

$$
\mu(x)=\frac{1}{4} x^{2} \frac{4 x-7}{4 x^{2}-3 x+2}
$$

Since $0 \leq \mu \leq 1$, the admissible interval for $x$ is $[1.75,5.2512]$.

Rearranging (6) and (7), we obtain:

$$
\begin{gathered}
R_{1 H}\left(\frac{x q}{\gamma}, \frac{q}{\gamma}, \gamma\right)=\frac{x^{2}\left[4(x-1)-(4 x-1)^{2} q\right] q}{(4 x-1)^{2} \gamma} \\
R_{2 L}\left(\frac{x q}{\gamma}, \frac{q}{\gamma}, \gamma\right)=\frac{x(x-1)-(4 x-1)^{2} \mu q}{(4 x-1)^{2} \gamma} q
\end{gathered}
$$

In particular, $R_{1 H}$ can be rewritten as

$$
R_{1 H}(x, \gamma)=\frac{4 x^{3}\left(4 x^{2}-3 x+2\right)(4 x-7)}{(4 x-1)^{2} \gamma}
$$

Moreover, we know from Lemma 1 that the monopoly revenues accruing to the leader are everywhere increasing in the quality level, so that (3) rewrites as follows:

$$
R_{M}(x, \gamma)=\frac{\left(4 x^{2}-3 x+2\right)\left(e^{-r t_{1}}-e^{-r t_{2}}\right)}{2 \gamma(4 x-1)^{3} e^{-r t_{2}}}
$$

Hence, the overall intertemporal profits of firm 1 are:

$$
\Pi_{1 H}(x, \gamma)=\left[\frac{\left(4 x^{2}-3 x+2\right)\left(e^{-r t_{1}}-e^{-r t_{2}}\right)}{2 \gamma(4 x-1)^{3} e^{-r t_{2}}}+\right.
$$




$$
\left.+\frac{4 x^{3}\left(4 x^{2}-3 x+2\right)(4 x-7)}{(4 x-1)^{2} \gamma}\right] \frac{e^{-r t_{2}}}{\bar{\theta}^{2} r}
$$

which, setting

$$
e^{-r t_{2}}=\eta ; \frac{\mu}{\eta}=\frac{e^{-r t_{1}}}{e^{-r t_{2}}}=\nu ; \frac{\eta}{\gamma \bar{\theta}^{2} r}=\frac{1}{c}\left(\frac{e^{-r t_{2}}}{r}\right)^{2}=\zeta
$$

can be further simplified as follows:

$$
\Pi_{1 H}(x, \nu, \zeta)=\left(8 x^{3}(4 x-7)+(\nu-1)(4 x-1)^{3}\right) \frac{4 x^{2}-3 x+2}{2(4 x-1)^{6}} \zeta
$$

The discounted flow of profits accruing to the follower is:

$$
\Pi_{2 L}(x, \zeta)=\frac{x\left(4 x^{2}-3 x+2\right)^{2}}{\gamma(4 x-1)^{6}} \cdot \frac{e^{-r t_{2}}}{\bar{\theta}^{2} r}=\frac{x\left(4 x^{2}-3 x+2\right)^{2}}{(4 x-1)^{6}} \cdot \zeta
$$

Observe that $\Pi_{1 H}(x, \nu, \zeta)>\Pi_{2 L}(x, \zeta)>0$ always.

\section{A.2 Proof of Proposition 2}

Consider first the leader's maximum problem. Fxpression (10) writes as follows:

$$
\begin{gathered}
\frac{\Pi_{1 L}}{\bar{\theta}^{2} e^{-r t_{2}}}=\frac{q_{H} q_{L}\left(q_{H}-q_{L}\right)}{\left(4 q_{H}-q_{L}\right)^{2}}+\frac{\left(e^{-r t_{1}}-e^{-r t_{2}}\right) q_{M}}{4 e^{-r t_{2}}}-\frac{e^{-r t_{1}} r c q_{M}^{2}}{\bar{\theta}^{2} e^{-r t_{2}}}= \\
=\frac{q_{H} q_{L}\left(q_{H}-q_{L}\right)}{\left(4 q_{H}-q_{L}\right)^{2}}-\gamma q_{M}^{2}+\frac{\left(e^{-r t_{1}}-e^{-r t_{2}}\right) q_{M}}{4 e^{-r t_{2}}}
\end{gathered}
$$

where $q_{M}=\bar{\theta}^{2}\left(e^{-r t_{1}}-e^{-r t_{2}}\right) /(8 r c)$ and net monopoly profits over $t \in\left[t_{1}, t_{2}\right]$ amount to:

$$
\pi_{1 M}=\frac{1}{4} \bar{\theta}^{2} q_{L} \int_{t_{1}}^{t_{2}} e^{-r t} d t-c q_{L}^{2}=\frac{\bar{\theta}^{2}\left(e^{-t_{2} r}-e^{-t_{1} r}\right)^{2}}{64 c r^{2}}
$$

Firm 2's profit flow (11) simplifies to:

$$
\frac{\Pi_{2 H}}{\bar{\theta}^{2} e^{-r t_{2}}}=4 \frac{q_{H}^{2}\left(q_{H}-q_{L}\right)}{\left(4 q_{H}-q_{L}\right)^{2}}-\frac{r c q_{H}^{2}}{\bar{\theta}^{2} e^{-r t_{2}}}=4 \frac{q_{H}^{2}\left(q_{H}-q_{L}\right)}{\left(4 q_{H}-q_{L}\right)^{2}}-\mu \gamma q_{H}^{2}
$$


The FOC for the leader w.r.t. $q_{L}$ is:

$$
\frac{\partial \Pi_{1 L}}{\partial q_{L}}=\frac{\bar{\theta}^{2} q_{H}^{2}\left(4 q_{H}-7 q_{L}\right)}{e^{r t_{2}}\left(4 q_{H}-q_{L}\right)^{3}}=0
$$

Therefore, the optimal strategy for firm 1 is given by the following best reply: ${ }^{11}$

$$
q_{L}=\frac{4}{7} q_{H}
$$

The behavior of firm 2 is summarized by:

$$
\frac{\partial \Pi_{2 H}}{\partial q_{H}}=\frac{2 q_{H}\left(8 q_{H}^{2}-6 q_{H} q_{L}+4 q_{L}^{2}-\left(4 q_{H}-q_{L}\right)^{3} \mu \gamma\right)}{\left(4 q_{H}-q_{L}\right)^{3}}=0
$$

The equilibrium at the first stage can now be characterized. Plugging (37) into (38) and rearranging, we get:

$$
\left.\operatorname{sign} \frac{\partial \Pi_{2 H}}{\partial q_{H}}\right|_{q_{L}=\frac{4}{7} q_{H}}=\operatorname{sign}\left\{\frac{288 q_{H}^{2}}{49}-\frac{13824 \mu \gamma q_{H}^{3}}{343}\right\}
$$

The r.h.s. expression in (39) has three critical points w.r.t. $q_{H}$, the unique relevant solution being

$$
q_{H}=\frac{7}{48 \mu \gamma}
$$

which yields the following equilibrium quality for firm 1:12

$$
q_{L}=\frac{4}{7} \frac{7}{48 \gamma_{2}}=\frac{1}{12 \mu \gamma}
$$

\footnotetext{
${ }^{11}$ Observe that (37) is the same best reply function identified by Choi and Shin (1992) in a one-shot game where quality is costless. This coincidence is due to our assumption that decreasing quality requires no additional costs.

${ }^{12}$ It can be verified that $q_{M}>q_{L}$ if

$$
t_{2}>\frac{1}{r} \ln \left[\frac{e^{r t_{1}}\left(3+2 e^{r t_{1}}\right)}{3}\right] .
$$

If $t_{1}=0$, the above condition simplifies to:

$$
t_{2}>\frac{\ln (5 / 3)}{r} \approx \frac{0.5108}{r} .
$$

However, notice that in the opposite case, where $q_{M}<q_{L}$, the leader could choose to develop the limit quality (41) and keep it 'asleep' until $t_{2}$.
} 
As a result, the discounted profits accruing to the leader over the horizon $\left[t_{1}, \infty\right)$ simplify as follows:

$$
\Pi_{1 L}(\nu, \zeta)=\left[\frac{1}{64}(1-\nu)^{2}+\frac{7}{2304}\right] \bar{\theta}^{4} \zeta
$$

while those of firm 2, supplying the high-quality good, are $\Pi_{2 H}=0$.

\section{A.3 Proof of Proposition 4}

In order to prove the proposition is sufficient to prove that there cannot be a sub-game perfect equilibrium with a low quality leader. Suppose the opposite. Then the leader would choose the quality level $q_{1 L}=\frac{7}{48 \gamma \mu}$, which induces zero profits for the follower. However, if the follower tries to undercut the leader's quality, it gains the profit function

$$
R_{2 L}\left(\frac{7}{48 \gamma \mu}, \frac{q_{L}}{\gamma \mu}\right)=\frac{1}{16} \frac{q_{L}}{\gamma \mu} \frac{49-1120 q_{L}+2688 q_{L}^{2}-2304 q_{L}^{3}}{\left(-7+12 q_{L}\right)^{2}}
$$

which is positive for very low $q_{L}$. Hence we obtained a contradiction. 


\section{References}

[1] Aoki, R. and T. Prusa (1997), "Sequential versus Simultaneous Choice with Endogenous Quality", International Journal of Industrial Organization, 15, 103-21.

[2] Beath, J., Y. Katsoulacos and D. Ulph (1987), "Sequential Product Innovation and Industry Evolution", Economic Journal, 97, 32-43.

[3] Cardon, J.H. and D. Sasaki (1998), "Preemptive Search and R\&D Clustering", RAND Journal of Economics, 29, 324-38.

[4] Choi, C.J. and H.S. Shin (1992), "A Comment on a Model of Vertical Product Differentiation", Journal of Industrial Economics, 40, 229-31.

[5] Denicolò, V. (1996), "Patent Races and Optimal Patent Breadth and Length", Journal of Industrial Economics, 44, 249-65.

[6] Donnenfeld, S. and S. Weber (1992), "Vertical Product Differentiation with Entry, International Journal of Industrial Organization, 10, 449-72.

[7] Donnenfeld, S. and S. Weber (1995), "Limit Qualities and Entry Deterrence", RAND Journal of Economics, 26, 113-30.

[8] Dutta, P.K., S. Lach and A. Rustichini (1995), "Better Late than Early: Vertical Differentiation in the Adoption of a New Technology", Journal of Economics and Management Strategy, 4, 563-89.

[9] Gallini, N. (1992), "Patent Policy and Costly Imitation", RAND Journal of Economics, 23, 52-63.

[10] Gabszewicz, J.J. and J.-F. Thisse (1979), "Price Competition, Quality and Income Disparities", Journal of Economic Theory, 20, 340-59.

[11] Gabszewicz, J.J. and J.-F. Thisse (1980), "Entry (and Exit) in a Differentiated Industry", Journal of Economic Theory, 22, 327-38.

[12] Gilbert, R. and C. Shapiro (1990), "Optimal Patent Length and Breadth", RAND Journal of Economics, 21, 106-12.

[13] Green J. and S. Scotchmer (1995), "On the Division of Profit in Sequential Innovation", RAND Journal of Economics, 26, 20-33. 
[14] Klemperer, P.D. (1990), "How Broad Should the Scope of Patent Protection Be?", RAND Journal of Economics, 21, 113-30.

[15] Lambertini, L. (1999), "Endogenous Timing and the Choice of Quality in a Vertically Differentiated Duopoly", Research in Economics (Ricerche Economiche), 53, 101-09.

[16] Lehmann-Grube, U. (1997), "Strategic Choice of Quality when Quality is Costly: The Persistence of the High-Quality Advantage", RAND Journal of Economics, 28, 372-84.

[17] Motta, M. (1992), "Cooperative R\&D and Vertical Product Differentiation", International Journal of Industrial Organization, 10, 643-61.

[18] Motta, M. (1993), "Endogenous Quality Choice: Price vs Quantity Competition", Journal of Industrial Economics, 41, 113-32.

[19] O’ Donoghue, T. (1998), “A Patentability Requirement for Sequential Innovations", RAND Journal of Economics, 29, 654-79.

[20] O' Donoghue, T., S. Scotchmer and J.F. Thisse (1998), "Patent Breadth, Patent Length, and the Pace of Technological Progress", Journal of Economics and Management Strategy, 7, 1-32.

[21] Rosenkranz, S. (1995), "Innovation and Cooperation under Vertical Product Differentiation", International Journal of Industrial Organization, 13, 1-22.

[22] Rosenkranz, S. (1997), "Quality Improvements and the Incentive to Leapfrog", International Journal of Industrial Organization, 15, 243-61.

[23] Scotchmer, S. (1991), "Standing on the Shoulders of Giants: Cumulative Research and the Patent Law", Journal of Economic Perspectives, 5, $29-41$.

[24] Scotchmer, S. (1996), "Protecting Early Innovators: Should SecondGenerations Products Be Patentable?", RAND Journal of Economics, 27, 322-31.

[25] Scotchmer, S. and J. Green (1990), "Novelty and Disclosure in Patent Law", RAND Journal of Economics, 21, 131-46. 
[26] Shaked, A. and J. Sutton (1982), "Relaxing Price Competition through Product Differentiation", Review of Economic Studies, 49, 3-13.

[27] Shaked, A. and J. Sutton (1983), "Natural Oligopolies", Econometrica, 51, 1469-83.

[28] van Dijk, T. (1996), "Patent Height and Competition in Product Improvements", Journal of Industrial Economics, 44, 151-67. 